\title{
Detetives do passado no mundo do futuro: divulgação científica, ensino de História e internet
}

\author{
Detectives of the past in the world of the future: \\ popularization of science, teaching History, and internet
}

Keila Grinberg*

Anita Almeida**

\section{Resumo}

O objetivo do texto é refletir sobre a divulgação científica, o ensino de História e as possibilidades que a internet oferece nesse campo. E, ao mesmo tempo, discutir uma experiência específica, a elaboração do site "Detetives do Passado", produzido pelas autoras e dedicado ao ensino de história.

Palavras-chave: divulgação científica; ensino de História; internet.

\section{Abstract}

The aim of this paper is to discuss the popularization of science, history teaching and the possibilities the Internet offers in this field. At the same time, we intend to discuss a specific experience: the website "Detetives do Passado" [Detectives of the Past], dedicated to the teaching of history and produced by the authors.

Keywords: popularization of science; history teaching; internet.

\section{OS HISTORIADORES E A INTERNET}

Já chamada de 'o quadro negro do futuro', antes do entretenimento online e do e-commerce, a internet, ao surgir, foi imediatamente atrelada a possibilidades de renovação de métodos de ensino, ${ }^{1}$ mesmo que hoje dê para ver que o mundo dos negócios avançou bem mais rápido no uso da rede do que o da educação. A ideia de aliar os avanços tecnológicos e da comunicação a novas formas de educar já seduzia professores e universidades desde pelo menos a década de 1960, com a criação das primeiras Universidades Abertas na Europa, dedicadas ao ensino a distância, mais ou menos na mesma época em

\footnotetext{
* Departamento de História, Universidade Federal do Estado do Rio de Janeiro (UniRio). Av. Pasteur, 458, Urca. 22290-240 Rio de Janeiro - RJ - Brasil. keila@pobox.com

** Departamento de História, Universidade Federal do Estado do Rio de Janeiro (UniRio). Av. Pasteur, 458, Urca. 22290-240 Rio de Janeiro - RJ - Brasil. anita.correialima@gmail
} 
que a linguagem da educação em massa começava a mudar, e a ênfase na palavra 'aprendizado' ganhava espaço em relação à quase démodé 'ensino'.

Mas o espaço que as chamadas novas tecnologias ganharam no campo da reflexão mais geral sobre Educação não parece ter encontrado correspondente similar na área de História. ${ }^{3}$ Para além da utilização do computador como ferramenta para construção de bancos de dados, principalmente por especialistas em história econômica, quantitativa ou demográfica - procedimento feito desde a década de 1960 -, até recentemente foram poucos os historiadores que se dedicaram a refletir sobre as mudanças que a rede mundial de computadores traria à pesquisa, à produção e à divulgação do conhecimento em História. ${ }^{4}$

Como bem notou Camila Dantas, os primeiros historiadores a chegarem à internet foram os amadores, seguidos por centros universitários e instituições de memória. Atualmente, projetos de divulgação científica em História na internet, a maioria localizada nos Estados Unidos, estão mesclados a reflexões mais amplas sobre os documentos produzidos em meio digital e as novas formas de realização de pesquisa acadêmica, como o projeto Digital History ${ }^{5}$, desenvolvido por Daniel J. Cohen e Roy Rosenzweig na George Mason University, talvez o primeiro a, ao dirigir-se igualmente a historiadores profissionais e amadores que elaboram projetos na internet, defender uma nova iden-

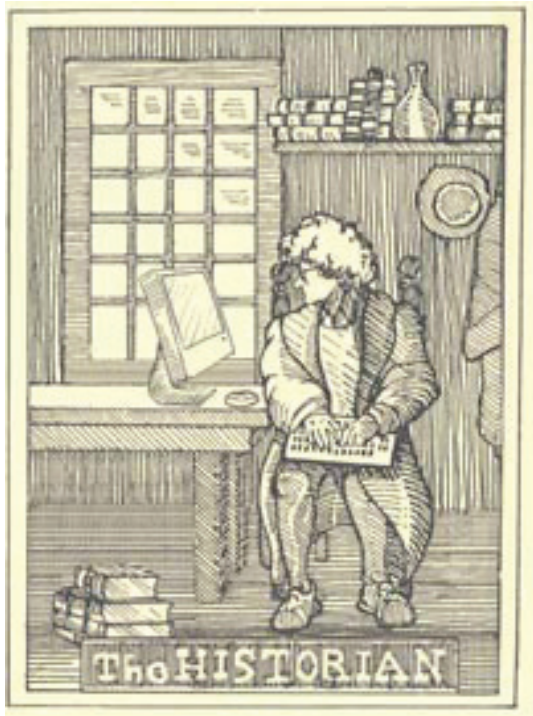
tidade para o historiador, expressa no logotipo do grupo. ${ }^{6}$

Hoje, a maioria das atividades de historiadores na internet é relativa à digitalização de documentos e de acervos de instituições, tanto para preservá-los quanto para torná-los disponíveis a pesquisadores e interessados que dificilmente a eles teriam acesso. No Brasil, além de iniciativas governamentais (como o Projeto Resgate, ${ }^{7}$ que, em esforço sem precedentes, digitalizou aproximadamente 150 mil documentos, com 1,5 milhão de páginas manuscritas, do acervo do Arquivo Histórico Ultramarino de Lis- 
boa), e da atuação de instituições como a Biblioteca Nacional e o Arquivo Nacional, fundamentais na discussão pública sobre a digitalização de acervos, são importantíssimas as iniciativas de grupos de pesquisa, que vêm elaborando projetos de digitalização e disponibilização online de documentos de outro modo praticamente inacessíveis ao pesquisador. Exemplar, nesse caso, é o trabalho do Laboratório de História Oral e Imagem (LABHOI) do Departamento de História da Universidade Federal Fluminense (UFF), que vem, mediante projetos coletivos ou individuais, se dedicando a digitalizar documentos, que incluem até mesmo acervos de outros países, como Cuba e Angola. ${ }^{8}$ Outro bom exemplo são projetos de realização colaborativa de bancos de dados digitais, como fazem pesquisadores do Centro de Pesquisas em História Social da Cultura (Cecult) da Unicamp e do Centro de Estudos do Oitocentos (CEO). ${ }^{9}$

Esses avanços na disponibilização e tratamento de fontes históricas nos colocam diante de novas e complexas questões: por exemplo, a de como preservar os documentos já criados em formato digital. ${ }^{10}$ Esse e outros desafios certamente acompanharão o trabalho dos historiadores do futuro.

Mas, passadas várias décadas da invenção do 'quadro negro do futuro', e apesar de iniciativas muito importantes ${ }^{11}$ que ajudam a mostrar a riqueza das possibilidades nessa área, os usos didáticos da internet, em sentido mais global, ainda parecem bem modestos.

\section{OS HISTORIADORES, O ENSINO DE HistóRIA}

\section{E A DIVULGAÇÃO CIENTÍFICA}

Uma questão que talvez esteja relacionada ao pouco uso da internet, de maneira mais específica, como ferramenta para a divulgação científica e o ensino de História, é o fato de que o interesse pelo próprio ensino de História, como área de reflexão e de produção, ainda é restrito na universidade. Um fenômeno que se observa é que, embora o campo tenha crescido bastante nos últimos anos, ainda são relativamente poucos os historiadores que se dedicam a pensar a forma como a História é ensinada nas escolas. Evidência disso é o fato de serem praticamente inexistentes os programas de pós-graduação no Brasil a se dedicarem ao assunto. Dos 63 cursos existentes na área de História no início de 2012, nenhum tem sua área de concentração dedicada ao Ensino de História. Há apenas alguns programas, como é o caso da Universidade Es- 
tadual de Londrina (UEL) ou da Universidade Federal da Paraíba (UFPB), que têm linhas de pesquisa dedicadas à pesquisa no campo. Para se ter ideia do contraste com outras áreas, existem hoje 72 cursos de pós-graduação no Brasil dedicados exclusivamente ao ensino de ciências - física, química, biologia, ciências da terra - e matemática, entre mestrado profissional (39), mestrado acadêmico e doutorado. Aliás, o número desses cursos cresceu tanto que eles deixaram de entrar na rubrica "Outros", na classificação das áreas de avaliação da Capes, para ter nomenclatura própria: "Ensino". ${ }^{12} \mathrm{O}$ mesmo é observado quando se analisa o número de professores universitários de História que se dedica à redação de livros didáticos e demais produtos dirigidos ao público escolar. Como exemplo, veja-se o caso do Programa Nacional do Livro Didático (PNLD) do Ministério da Educação. Na análise dos livros a serem adotados em 2012, há vários professores universitários de História avaliando as coleções, mas poucos escrevendo. ${ }^{13}$ Além disso, um aspecto da questão que precisa ser mencionado é que a Capes, por decisão dos comitês de área - e é assim na área de História - não considera o livro didático como produção intelectual qualificada dos pesquisadores, item de fundamental importância na avaliação dos programas de pós-graduação. ${ }^{14}$

Há alguns indícios, no entanto, de que esse estado de coisas pode estar mudando - e para melhor. Nesse ponto, as agências de fomento têm ocupado papel importante, tanto o CNPq, através do prêmio José Reis de divulgação científica e tecnológica, quanto a Faperj, por exemplo, por meio dos editais de Difusão e Popularização da Ciência e Tecnologia no Estado do Rio de Janeiro, existente pelo menos desde 2007, e de Apoio à Produção de Material Didático para Atividades de Ensino e/ou Pesquisa, existente desde 2009. E há o sucesso de iniciativas recentes, no campo da divulgação, como a Revista de História da Biblioteca Nacional, ${ }^{15}$ ou no campo da pesquisa, como as atividades do grupo de pesquisa Oficinas de História, composto por pesquisadores de várias instituições de ensino e pesquisa do país, que desenvolve, entre outras atividades, o projeto Caixa de História. ${ }^{16}$

\section{O passado, A História E AS QUESTÕEs DO FUTURO}

Voltando aos historiadores e à internet, no momento parece que estamos diante de vários desafios. O primeiro é o já mencionado anteriormente, que 
mobiliza, além de historiadores, arquivistas e cientistas da informação: o desafio da preservação da documentação, produzida em vários suportes, inclusive a própria internet.

Outro desafio é a reflexão sobre a forma como o público em geral tem dialogado com os sites que disponibilizam documentos históricos, como processos criminais, registros de batismo, fotografias, relatórios oficiais etc. Hoje é muito mais fácil, para estudantes e interessados em geral, obter informações retiradas das próprias fontes históricas, algo anteriormente feito apenas pelos historiadores que sabiam localizá-las no mundo real.

Nesse sentido, a maior facilidade em consultar documentos de épocas e locais variados significa uma maior divulgação do conhecimento histórico? Por conta da internet, estaríamos mais perto de uma História Pública, no sentido atribuído ao termo pelo National Council on Public History, qual seja, o de tornar a História, seus procedimentos metodológicos e suas referências mais acessíveis ao grande público ${ }^{17}$

Acreditamos que não. Sendo um pouco pessimistas, talvez um dos efeitos de tanta facilidade de acesso, neste caso principalmente a textos, possa até ter sido o contrário: apesar de ainda não termos estatísticas a respeito, é flagrante o aumento de plágios em trabalhos acadêmicos, e não há professor universitário que não tenha uma história triste para contar sobre a ocasião em que se sentiu um policial, procurando crimes de autoria no Google. ${ }^{18}$

Talvez esteja aí a maior dificuldade, e ao mesmo tempo o maior desafio, que une tanto o ensino de História quanto a divulgação científica na internet. Ao invés de apenas combater o plágio - que naturalmente já existia bem antes de serem criados os mecanismos de busca -, trata-se de evidenciar, através da internet, o processo de produção do conhecimento, a começar pela própria noção de autoria, tão discutida no âmbito da criação artística. ${ }^{19}$ Afinal, a acessibilidade a textos e documentos proporcionada pela rede mundial de computadores, para ser bem usada, requer conhecimentos prévios sobre confiabilidade e relevância das informações a serem obtidas na internet. Sem elas, o leitor - ou o usuário do sistema - não consegue avançar na leitura e na produção de texto (de qualquer texto, de uma tese a um comentário em um blog).

Como fazer isso? Um caminho possível é criar mecanismos que permitam ao usuário - leitor, estudante, qualquer que seja seu login - conhecer as etapas do processo de produção do conhecimento em História. Assim, saber ler do- 
cumentos de época, contextualizá-los, criticá-los, cotejar as informações obtidas com outros documentos e com outros textos e verificar a procedência de informações obtidas nesses textos são alguns dos procedimentos que ajudam as pessoas a observar, analisar e classificar informações de qualquer natureza. No caso das informações de natureza histórica, isso é fundamental, tanto para os estudantes de História, quanto para os interessados no assunto.

Refletir sobre o processo de produção do conhecimento histórico talvez não seja o objetivo inicial das pessoas interessadas em História - público potencial das ações de divulgação científica - que buscam a internet como forma de aprimorar seus conhecimentos. Mas talvez esta seja uma surpresa que os historiadores podem reservar a seus leitores: além de divulgar o conhecimento produzido nas universidades, divulgar também seu processo de produção. E a internet, para isso, é um meio extraordinário.

\section{O site "Detetives do Passado"}

O site "Detetives do Passado" foi pensado como um espaço de atividades de investigação e pesquisa escolar, voltado para alunos da Educação Básica, tanto dos últimos anos do ensino fundamental, como do ensino médio. Ainda em fase experimental, nasceu da tentativa de lidar com algumas questões que envolvem o uso da internet no ensino de História, através do desafio que é a elaboração de um material específico. E é preciso dizer que se é possível imaginarmos que as possibilidades nessa área são amplas, as dificuldades também não são pequenas. Por ser um campo ainda novo, os procedimentos e recursos didáticos criados no mundo virtual da internet ainda não foram ampla e globalmente testados, por alunos e professores, e tampouco existem práticas consolidadas. Esse é um campo em que ainda estamos mais ou menos tateando no escuro. E foi assim, como um pequeno experimento, em área que se imagina tão vasta e ainda pouco explorada, que o site foi desenvolvido.

O Projeto foi financiado pela Faperj, mediante o Edital de "Difusão e Popularização da Ciência e Tecnologia no Estado do Rio de Janeiro", de 2007, e obteve apoio da Faperj e do CNPq, através do Programa de Apoio a Núcleos de Excelência (Pronex) "Dimensões da cidadania no Oitocentos", liderado pelo prof. dr. José Murilo de Carvalho (UFRJ). E está disponível na página do Núcleo de Documentação, História e Memória da UniRio (Numem). ${ }^{20}$ 
Como ajudar os alunos a estudar história navegando na rede? Uma das grandes possibilidades que a internet trouxe foi justamente a da facilidade de obter informações, inclusive sobre temas históricos. Todo mundo sabe que basta digitar um evento, uma data, um personagem, sobre qualquer lugar do planeta, em qualquer site de busca, que em poucos segundos há na tela bem mais resultados do que alguém é capaz de acessar. A dificuldade de estudar história usando a internet está muito longe de estar relacionada à escassez de recursos, e mesmo considerando apenas os sites de instituições de pesquisa que hoje dão acesso a documentos digitalizados, ainda assim estamos falando de milhões de documentos. A dificuldade certamente não está na quantidade de material disponível, e quase poderíamos dizer que, ao contrário, o perigo é ser soterrado. Na internet, então, o mais importante é saber fazer escolhas e ter um roteiro de pesquisa.

Voltando à ideia da importância de o aluno, ao mesmo tempo em que tem acesso a determinado conhecimento histórico, ter também contato com o processo de produção desse conhecimento, o Projeto foi elaborado com a preocupação, por um lado, de divulgar pesquisas recentes na área de História e, por outro, mas não menos importante, de poder funcionar como uma ferramenta para 'aprender a investigar'.

Assim foi desenvolvida a ideia de oficinas, cuja realização se dá através do contato com as fontes, a matéria-prima dos historiadores. ${ }^{21} \mathrm{~A}$ metodologia de trabalho a ser desenvolvida nas oficinas - tanto na sua elaboração quanto no momento de serem colocadas em prática por professores e alunos - segue como inspiração a perspectiva do método indiciário, tal como explicitada por Carlo Ginzburg em Mitos, emblemas e sinais. ${ }^{22}$ Com base no paralelo com o trabalho do detetive, o objetivo foi mostrar como o conhecimento histórico é, necessariamente, fruto de uma investigação. O objetivo último, no entanto, era que os alunos, ao realizarem as oficinas propostas, exercitassem a autonomia. $\mathrm{E}$ assim fossem animados a seguir navegando pelo enorme arsenal de informações - inclusive históricas - que a internet fornece. Mas com seus próprios olhos.

Como um projeto piloto, foram criadas oito atividades, todas com o tema da escravidão no século XIX. A escolha do tema da escravidão esteve relacionada a dois contextos. Em primeiro lugar, esse é um tema em que as pesquisas históricas se desenvolveram notavelmente nos últimos anos. Além disso, o 
ensino de história da África e cultura afro-brasileira foi tornado obrigatório no Brasil desde a promulgação da Lei 10.639/2003, e regulamentado através das "Diretrizes curriculares nacionais para a educação das relações étnico-raciais e para o ensino de história e cultura afro-brasileira e africana”, de 2004. Era possível, então, que o material se inserisse no conjunto das várias iniciativas que têm sido realizadas no sentido de promover o ensino do tema.

Para a criação das oficinas, optamos por selecionar casos e documentos reais, conservados em arquivos públicos brasileiros e de outros países, de maneira que os alunos do ensino fundamental e médio pudessem ter a experiência de lidar com documentação utilizada nas pesquisas históricas.

As oito oficinas foram organizadas cronologicamente. A primeira, "Rebeldia no Engenho Santana”, baseia-se em um acordo ou 'tratado de paz', o “Tratado proposto a Manoel da Silva Ferreira pelos seus escravos durante o tempo em que se conservaram levantados", enviado pelos escravos do engenho Santana a seu senhor, por volta de 1789. Esse e outros documentos relativos ao engenho baiano estão depositados na Torre do Tombo, em Portugal, e foram utilizados pela primeira vez pelo historiador Stuart Schwartz, em seu livro Segredos internos. ${ }^{23}$ Já a última oficina, "Padeiros livres, padeiros escravos e cartas de alforria falsas", gira em torno de um documento, conservado no Arquivo Público do Estado do Rio de Janeiro e escrito no ano de 1934, mas que remete a acontecimentos que se passaram nos últimos anos da escravidão, quando escravos e livres trabalharam lado a lado. Os outros casos analisam o processo de uma escrava contra seu senhor, no Desterro (Florianópolis), em 1813, a história de um 'preto forro’ que em 1819, no Rio de Janeiro, pede autorização para exercer a profissão de sangrador, e a vida em uma grande fazenda no Vale do Paraíba fluminense, observada a partir de um quadro pintado em 1844. Temos ainda a história da luta de um grupo de africanos libertos para conseguir a ajuda dos ingleses no intuito de voltar para a África e fundar uma cidade em Cabinda, em 1851, além de uma oficina sobre o trabalho dos escravos carregadores de piano, na década de 1860, no Rio de Janeiro, em que se contou com a ajuda de um romance de Machado de Assis. E, finalmente, o tema da abolição, investigado com base na poesia de Castro Alves.

Além dos documentos-chave usados na montagem de cada oficina, elas foram preenchidas com uma série de outras fontes, mapas, aquarelas, relatos de viajantes, trechos de romances, algumas tabelas com dados consolidados e 
citações de trechos de obras historiográficas, de maneira que todo esse material pudesse ser analisado, comparado e inter-relacionado, de diversas formas, durante a realização da atividade.

Todas as oficinas foram construídas sobre um esquema básico: o caso, a tarefa, o passo a passo e a solução. A partir do contato inicial com o 'caso', o aluno precisa consultar algumas 'pistas' (fontes de pesquisa), que são acessadas ao longo do passo a passo, e que ajudam na realização da tarefa proposta. Ele conhece a 'solução' - ligada ao documento central, com base no qual aquela oficina foi montada - apenas no final. A ideia era que, invertendo a lógica mais comum nos livros didáticos, o aluno não usasse as fontes apenas como ilustração, ou que não fosse incentivado a analisar as fontes somente depois de já ter lido sobre aquele assunto, como um complemento do aprendizado, mas, ao contrário, que as fontes fossem indispensáveis para a elaboração da atividade. Não há, portanto, textos básicos ou explicativos sobre o tema, nas oficinas.

Para a solução dos casos, os alunos são convidados a participar, ora como pessoa próxima, ora como o próprio protagonista da história, escravo, descendente ou liberto. Escolhemos abordar histórias que colocassem em evidência a diversidade da experiência de escravos, libertos e seus descendentes no século XIX, ainda que todas essas experiências estivessem ligadas, de uma maneira ou de outra, pela marca do cativeiro. Além disso, pretendemos criar situações em que os estudantes pudessem viver a experiência de ficar no lugar de pessoas reais, que viveram situações reais, e que, em alguma medida, e apesar da escravidão, puderam ser sujeitos da sua própria história.

E por falar em protagonistas, o nosso objetivo era que o aluno pudesse ter a experiência de ser o protagonista em relação, também, ao seu processo de aprendizagem, aprendendo a olhar, julgar, medir e comparar, a criar hipóteses de investigação, a sustentar uma argumentação e, afinal, a criar sua própria maneira de ver as coisas. E que assim pudesse ficar um pouco mais preparado para navegar, e pegar bons peixes, no mar que é a internet. Esse foi o nosso desejo, a nossa aposta.

\section{NOTAS}

${ }^{1}$ A expressão é do Secretário de Educação de Bill Clinton, dita em 1996, por ocasião da implantação da ligação, por telefone fixo, das salas de aula da Califórnia com a internet. 
Citada em BRIGGS, Asa; BURKE, Peter. Uma história social da mídia: de Gutenberg à internet. Rio de Janeiro: Jorge Zahar, 2006. p.303.

${ }^{2}$ A Universidade Aberta da Grã-Bretanha (Open University) formou sua primeira turma em 1971. A expressão ‘sociedade de aprendizagem', depois de ter sido utilizada pelo segundo reitor da nova universidade das Nações Unidas, foi usada no título de estudo produzido pela Comunidade Europeia em 1995. BRIGGS; BURKE, 2006, p.307-308.

${ }^{3}$ Ver, a respeito, GALLO, Silvio; RIVERO, Cléa Maria (Org.) A formação de professores na sociedade do conhecimento. Bauru (SP): Edusc, 2004. Ver também o interessante, embora um tanto ingênuo, vídeo sobre o impacto das novas tecnologias na educação, postado por Bruno Leal na rede social Café Historia. Disponível em: cafehistoria.ning.com/ video/o-impacto-das-novas; Acesso em: 5 mar. 2012. Outra forma de acessar o vídeo é pelo YouTube: www.youtube.com/watch?v=Uppyy6eRcBQ\&feature=player_embedded; Acesso em: 5 mar. 2012.

${ }^{4}$ Ver, a respeito, FIGUEIREDO, Luciano. História e informática: o uso do computador. In: CARDOSO, Ciro Flamarion; VAINFAS, Ronaldo (Org.) Domínios da História. Rio de Janeiro: Campus, 1997. Para uma história da relação entre os historiadores e a internet, ver a excelente dissertação de mestrado de DANTAS, Camila Guimarães. O passado em bits: memórias e histórias na internet. Dissertação (Mestrado) - Programa de Pós-Graduação em Memória Social, UniRio. Rio de Janeiro, 2008.

${ }^{5}$ DANTAS, 2008, p.50. Ver o projeto Digital History em: chnm.gmu.edu/digitalhistory/; Acesso em: 5 mar. 2012.

${ }^{6}$ A imagem também foi citada em DANTAS, 2008, p.49.

${ }^{7}$ O Banco de Dados do Projeto Resgate pode ser acessado no Centro de Memória Digital da Universidade de Brasília, em www.cmd.unb.br/resgate_index.php.

${ }^{8}$ As atividades do LABHOI podem ser acessadas em www.historia.uff.br/labhoi/. Ver, por exemplo, os projetos de digitalização desenvolvidos por Mariza de Carvalho Soares, como “A escravidão africana nos arquivos eclesiásticos”. Disponível em: www.historia.uff.br/ curias/modules/tinyd0/; Acesso em: 5 mar. 2012.

${ }^{9}$ Para acessar os projetos desenvolvidos por esses grupos de pesquisa ver, respectivamente, www.unicamp.br/cecult/ e www.ceo.historia.uff.br/.

${ }^{10}$ Ver, por exemplo, os projetos desenvolvidos pelo Arquivo Nacional (www.arquivonacional.gov.br) e pela Biblioteca Nacional (www.bn.br). A questão da relação entre a História e a preservação de documentos criados em suporte digital vem sendo desenvolvida por Camila Guimarães Dantas em seu projeto de doutorado, no Programa de Pós-Graduação em Memória Social da UniRio.

${ }^{11} \mathrm{O}$ Arquivo Nacional possui um grande Projeto - "O Arquivo Nacional e a História Luso-Brasileira” - elaborado com base na documentação da instituição, referente aos séculos XVI ao XIX, e voltado, ao mesmo tempo, para a difusão do acervo e para a sala de aula. Disponível em: www.historiacolonial.arquivonacional.gov.br/cgi/cgilua.exe/sys/start. 
htm?sid=134; Acesso em: 5 mar. 2012. Ver também, para um exemplo na universidade, o Projeto "Pesquisa e Produção de Material Didático para o Ensino de História do Brasil Colonial e República", coordenado pelos professores Luiz Carlos Villalta e Priscila Brandão Antunes, da UFMG. Disponível em: www.fafich.ufmg.br/pae/; Acesso em: 5 mar. 2012. A ideia aqui não é, nem o espaço permite, a de um inventário dos diversos projetos em andamento nas universidades e em outras instituições de pesquisa. Mas um inventário desse tipo seria importante. Como exemplo de portal dedicado ao Ensino de História em outros países, ver teachinghistory.org/, da George Mason University, Estados Unidos; Acesso em: 5 mar. 2012.

${ }^{12}$ Os dados podem ser verificados no site da Capes: www.capes.gov.br. Para os dados sobre a área de História, ver diretamente: conteudoweb.capes.gov.br/conteudoweb/Projet oRelacaoCursosServlet $?$ acao $=$ pesquisarIes $\&$ codigoArea $=70500002 \&$ descricaoArea $=\mathrm{CI} \% \mathrm{C}$ ANCIAS+HUMANAS+\&descricaoAreaConhecimento=HIST\%D3RIA\&descricaoAreaAv aliacao=HIST\%D3RIA; Acesso em: 5 mar. 2012 (o site foi atualizado em 2 mar. 2012). Para os dados sobre a área de Ensino, ver: conteudoweb.capes.gov.br/conteudoweb/ProjetoRel acaoCursosServlet 2 acao $=$ pesquisarIes $\&$ codigoArea $=90200000 \&$ descricaoArea $=$ MULTIDI SCIPLINAR $+\&$ descricaoAreaConhecimento $=$ ENSINO\&descricaoAreaAvaliacao $=$ ENSI NO; Acesso em: 5 mar. 2012.

${ }^{13}$ Ver, para o ensino fundamental, o Guia de livros didáticos: PNLD 2011: História (2010). Brasília: Ministério da Educação, Secretaria de Educação Básica. Para o ensino médio, o Guia de livros didáticos: PNLD 2012: História (2011). Os volumes podem ser acessados em: www.fnde.gov.br/index.php/pnld-guia-do-livro-didatico; acesso em: 5 mar. 2012.

${ }^{14} \mathrm{O}$ Conselho Técnico-Científico da Educação Superior da Capes aprovou em 24 de agosto de 2009 o Roteiro para Classificação de Livros, que serviu de orientação para a classificação de livros com base na avaliação trienal de 2010. Disponível em: www.capes.gov.br/images/ stories/download/avaliacao/Roteiro_livros_Trienio2007_2009.pdf; Acesso em: 5 mar. 2012). Por decisão da área de História, os livros didáticos elaborados por pesquisadores devem ser considerados como 'inserção social', item de menor importância na avaliação dos programas de pós-graduação. Os critérios adotados pela área de História estão no Relatório de Avaliação 2007-2009 - trienal 2010. Disponível em: trienal.capes.gov.br/wp-content/uploads/2010/12/ HIST\%C3\%93RIA-RELAT\%C3\%93RIO-DE-AVALIA\%C3\%87\%C3\%83O-FINAL-dez10. pdf; Acesso em: 5 mar. 2012.

${ }^{15}$ A Revista tem uma seção - "Sala de aula" - voltada especificamente para o ensino de História. Disponível em: www.revistadehistoria.com.br/sala-de-aula; Acesso em: 5 mar. 2012.

${ }^{16}$ Sobre o grupo Oficinas de História, suas atividades e sua produção acadêmica, ver: www. oficinasdehistoria.com.br/; Acesso em: 5 mar. 2012. O projeto Caixa de História pode ser conhecido em projetocaixadehistoria.blogspot.com/; Acesso em: 5 mar. 2012.

${ }^{17}$ National Council on Public History. Disponível em: ncph.org/cms/; Acesso em: 5 mar. 2012. 
${ }^{18}$ Ver, a respeito, o artigo de Brent Staples, "Cutting and Pasting: a senior thesis", publicado no New York Times em 12 jul. 2010. Disponível em: www.nytimes.com/2010/07/13/ opinion/13tue4.html?_r=1\&src=me\&ref=opinion; Acesso em: 8 set. 2010.

${ }^{19}$ Neste sentido, são conhecidas as proposições de Gilberto Gil para a flexibilização da legislação do direito autoral. Ver o artigo de Gil, "Por uma reforma da lei do direito autoral", publicado em $O$ Globo em 11 nov. 2007. Disponível em: www.creativecommons.org.br/ index.php?option=com_content\&task=view\&id=90\&Itemid=1; Acesso em: 5 mar. 2012. Alguns professores vêm encontrando alternativas interessantes para lidar com o plágio realizado pelos alunos na internet, principalmente da Wikipedia: ver, por exemplo, o projeto de atualização de verbetes da Wikipedia desenvolvido por Juliana Bastos Marques, do Departamento de História da UniRio. Mais informações sobre o projeto podem ser encontradas em: wikipedianauniversidade.blogspot.com/; Acesso em: 5 mar. 2012.

${ }^{20}$ A página do Numem é historiaunirio.com.br/numem/index.php, e o endereço do Projeto é www.historiaunirio.com.br/numem/detetivesdopassado/. Como o acesso à internet ainda é difícil em muitas regiões e escolas, foi feita uma edição em CD-ROM, com o mesmo conteúdo do site, para ser distribuída às escolas.

${ }^{21}$ As oficinas tiveram como inspiração as webquests, atividades de ensino baseadas na web, principalmente o site canadense Mystery Quests: www.mysteryquests.ca/indexen.html; Acesso em: 5 mar. 2012.

${ }^{22}$ GINZBURG, Carlo. Sinais: raízes de um paradigma indiciário. In: Mitos, emblemas e sinais: morfologia e história. São Paulo: Companhia das Letras, 1990. p.143-179.

${ }^{23}$ SCHWARTZ, Stuart. Segredos internos: engenhos e escravos na sociedade colonial. São Paulo: Companhia das Letras, 1985. As referências completas dos documentos utilizados nas oficinas podem ser encontradas no próprio site.

Artigo recebido em 10 de janeiro de 2012. Aprovado em 22 de março de 2012. 